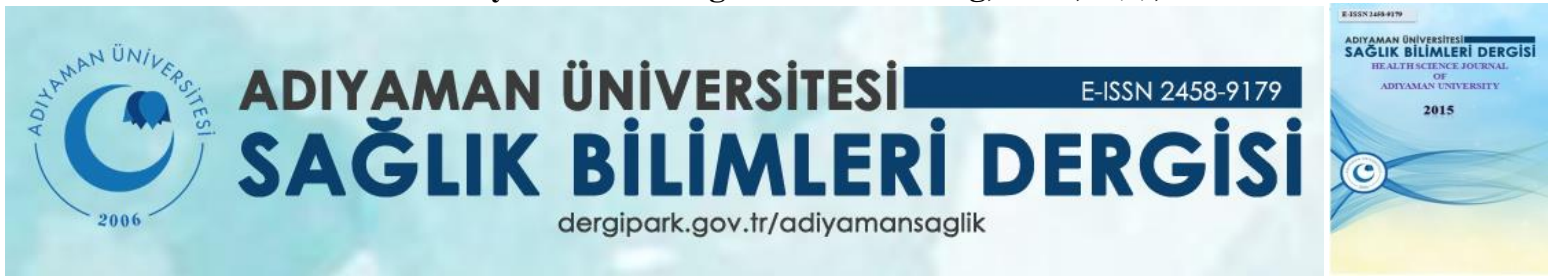

\title{
Araștırma/Research
}

\section{Lomber Disk Hernisi Olan Hastaların Sağlıklı Yaşam Biçimi Davranışlarının ve Öz-Bakım Gücünün Belirlenmesi}

\section{Yelda CANDAN DÖNMEZ ${ }^{1}$, Meryem YAVUZ VAN GIERSBERGEN ${ }^{1}$, Arzu ASLAN BASLI ${ }^{2}$, Mahbube Dilek YILDIZ ${ }^{3}$, Emel YILDIZ ${ }^{3}$}

\footnotetext{
${ }^{1}$ Ege Üniversitesi Hemşirelik Fakültesi Cerrahi Hastalıkları Hemşireliği Anabilim Dalı

${ }^{2}$ Manisa Celal Bayar Üniversitesi Sağlık Bilimleri Fakültesi, Cerrahi Hastalıkları Hemşireliği Anabilim Dalı

${ }^{3}$ Ege Üniversitesi Sağlık Uygulama ve Araştırma Merkezi Beyin ve Sinir Cerrahisi Anabilim Dalı
}

\section{$\ddot{O} \mathbf{z}$}

Amaç: Tanımlayıcı ve kesitsel tipte olan çalışma, lomber disk hernisi olan hastaların sağlıklı yaşam biçimi davranışlarını ve öz-bakım gücünü incelemek amacıyla yapıldı.

Yöntem: Bir üniversite hastanesinin Beyin ve Sinir Cerrahisi Anabilim Dalı'nda lomber disk hernisi tanısı ile yatan 240 hasta çalışmaya dahil edildi. Araştırmanın verileri Kişisel Bilgi Formu, Sağlıklı Yaşam Biçimi Davranışları Ölçeği II (SYBDÖ) ve Öz- Bakım Gücü Ölçeği (ÖBGÖ) kullanılarak topland. Verilerin analizinde PASW 18 paket programı kullanıldı.

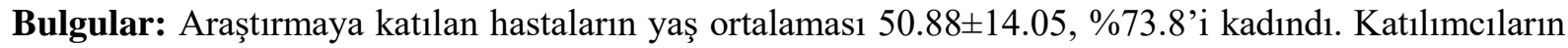
lomber disk hernisi tanısı konulma zamanı ortalama 5.8 yıldı ve \%39.02'sinin bel ağrısı şikayeti ile hastaneye başvurduğu saptandı. Lomber disk hernili bireylerin Sağlıklı Yaşam Biçimi Davranışları Ölçeği puan ortalaması 125.09 \pm 21.05 ve Öz-Bakım Gücü Ölçeği puan ortalaması 73.32 \pm 24.36 olarak belirlendi. Yaş, beden kitle indeksi, sosyoekonomik durum ve kronik hastalık varlığının sağlıklı yaşam biçimi davranışlarını etkilediği saptandı. Kırk yaşın altında, çalışan ve lomber disk hernisi ile ilgili önceden tedavi gören hastaların öz- bakım gücünün daha yüksek olduğu saptandı.

Sonuç: Hastaların öz-bakım gücünün ve sağlıklı yaşam biçimi davranışlarının orta düzeyde olduğu belirlendi. Lomber disk hernisinin fiziksel aktivite seviyelerini olumsuz yönde etkilediği saptandı.

Anahtar kelimeler: lomber disk hernisi, sağlık yaşam biçimi, öz-bakım

\begin{tabular}{l}
\hline Yazışmadan Sorumlu Yazar \\
\hline Arzu ASLAN BASLI \\
Manisa Celal Bayar Üniversitesi Sağlık Bilimleri \\
Fakültesi, Cerrahi Hastalıkları Hemşireliği Anabilim \\
Dalı \\
Tel : +90 0 (236) 2330904 - 5850 \\
Email: arzuaslan.mcbu@gmail.com \\
\hline
\end{tabular}

Doi: 10.30569.adiyamansaglik.545233

\begin{tabular}{ll}
\hline Geliş Tarihi: & $\mathbf{2 7 . 0 3 . 2 0 1 9}$ \\
\hline Kabul Tarihi: & $\mathbf{2 4 . 0 6 . 2 0 1 9}$ \\
\hline
\end{tabular}




\section{Determination of Healthy Lifestyle Behaviors and Self-Care Agency of Patients with Lumbar Disc Hernia}

\section{Abstract}

Aim: The descriptive and cross-sectional study was conducted to investigate the healthy lifestyle behaviors and self-care agency of patients with lumbar disc herniation.

Methods: A total of 240 patients with lumbar disc herniation were included in the study in the Department of Brain and Nerve Surgery of a university hospital. The data of the study were collected by using personal information form, Health Promoting Lifestyle Profile Scale II and Self-Care Agency Scale. PASW 18 package program was used for statistical analysis.

Results: The mean age of the patients was $50.88 \pm 14.05$ years and $73.8 \%$ of the patients were female. The mean time of diagnosis of lumbar disc herniation was 5.8 years and $39.02 \%$ of the participants were admitted to the hospital with low back pain. The mean score of Health Promoting Lifestyle Profile Scale II of the patients with lumbar disc herniation was $125.09 \pm 21.05$ and the mean score of Self-Care Agency Scale was $73.32 \pm 24.36$. Age, body mass index, socioeconomic status and presence of chronic disease were found to affect healthy lifestyle behaviors. Patients who were under 40 years of age and who were previously treated for lumbar disc herniation had higher self-care agency.

Conclusion: It was determined that the self-care agency and healthy lifestyle behaviors of the patients were moderate. It was observed that lumbar disc herniation had a negative effect on physical activity levels.

Keywords: lomber disc hernia, healthy lifestyle, self-care

\section{Giriş}

Toplumu oluşturan bireylerin \%80'i yaşamlarının herhangi bir kısmında bel ağrısından yakınmaktadır. Bel ağrısının en sık nedenlerinden birisi lomber disk hernisidir. Lomber disk hernisi kalıcı fonksiyonel kayıplara ve iş gücü kaybına neden olan en önemli sağlık sorunlarından biridir $(1,2)$. Lomber disk hernisi 30-50 yaş erkeklerde ve sıklıkla lomber 4- 5 ya da lomber 5- sakral 1 vertebraları arasında görülür $(3,4,5)$. Lomber disk hernisinin en sık nedeni bölgesel mekanik bozukluklardır. Ani tek bir travmadan çok zaman içinde tekrarlayıcı, birikimli travmaların önemli rolü vardır. Ağır yaşam ve çalışma koşulları, kötü statik ve dinamik postür, yanlış vücut mekaniklerinin kullanımı, karın ve sırt kaslarının güç ve esnekliğinde azalma, sigara içme gibi risk faktörlerinin bel ağrısına sebep olduğu bilinmektedir $(1,3,4,6,7)$.

Lomber disk hernisi kişinin fonksiyonları üzerinde önemli bir etkiye sahiptir. Bel ağrılı hastalarda ağrı, spazm, kas kuvvetinin azalması ve bozulan postür sonucu fiziksel dayanıklılık 
azaltmakta ve hastanın fonksiyonel kapasitesi ve yaşam kalitesi olumsuz yönde etkilenmektedir $(2,6,8,9)$. Kişinin ayakta durmasından, yürüme, eğilme, ağırlık kaldırma, seyahat, sosyal yaşam, giyim ve seksüel ilişkisine kadar birçok aktivitesini etkilemektedir $(5,10)$.

Lomber disk hernisi olan hastada sağlıklı yaşam biçimi davranışlarının geliştirilip, sürdürülmesini sağlamak ve öz-bakımını yükseltmek hemşirenin sorumlulukları arasındadır. $\mathrm{Bu}$ nedenle hemşirelerin, bakım verdikleri hastanın sağlıklı yaşam biçimi davranışlarını ve özbakımını değerlendirmeleri, hastanın gereksinimlerine yönelik yardımı ve bakımı optimal düzeyde planlayıp uygulayabilmelerine firsat verecektir $(10,11)$.

Bu çalışmada amaç; lomber disk hernisi olan hastaların sağlıklı yaşam biçimi davranışlarını ve öz-bakım gücünü incelemektir.

\section{Gereç Yöntem}

Araştırmanın Tipi ve Zamanı: Tanımlayıcı ve kesitsel tipte olan çalışma Mart 2016- Eylül 2017 tarihleri arasında yürütüldü.

Araştırmanın Evren ve Örneklemi: Araştırmanın evrenini bir üniversite hastanesinin Beyin ve Sinir Cerrahisi Anabilim Dalı'nda lomber disk hernisi tanısı ile yatan hastalar oluşturdu. Araştırmanın örneklemini; lomber disk hernisi tanısı ile yatan, 18 yaş üzerinde, bilinci açık ve soruları cevaplayabilecek, iletişime ve iş birliğine açık olan, görme ve işitme gibi duyusal kayıpları bulunmayan, bilinç ya da psikiyatrik problemi olmayan, araştırmaya katılmayı kabul eden hastalar oluşturdu. Araştırmaya katılmayı kabul etmeyen, anket formu ve ölçekleri sağlıklı biçimde doldurmaya engel ruhsal ve fiziksel (hareket kısıtlılı̆gı) durumu bulunan, nörolojik ve psikiyatrik problemi olan bireyler araştırmaya alınmadı. Bu araştırmaya 240 gönüllü dahil edildi. Araştırmada örneklem seçimine gidilmedi, araştırmanın yürütüldüğü tarihlerde belirlenen kriterlere uyan gönüllüler araştırmaya dahil edildi.

Veri Toplama Araçları: Araştırmanın verileri; araştırmanın yürütüldüğü klinikte, hasta odasında yüz yüze görüşülerek toplandı. Veri toplama aracı olarak Kişisel Bilgi Formu, Sağlıklı Yaşam Biçimi Davranışları Ölçeği II (SYBDÖ) ve Öz- Bakım Gücü Ölçeği (ÖBGÖ) kullanıldı. Kişisel Bilgi Formu hasta ile görüşülerek araştırmacı tarafından doldurulmuş olup, Sağlıklı Yaşam Biçimi Davranışları Ölçeği II (SYBDÖ) ve Öz- Bakım Gücü Ölçeği (ÖBGÖ)'ni hastanın doldurması istendi.

Kişisel Bilgi Formu: Araştırmacılar tarafından literatür doğrultusunda geliştirilen sosyodemografik verileri ve hastalığa ilişkin bilgileri içeren ve toplam 17 sorudan oluşan bir formdur. 
Sağlıklı Yaşam Biçimi Davranışları Ölçeği II: Walker ve ark. (1987) tarafından geliştirilmiş, 1996 yılında tekrar revize edilmiştir (13). 2008 yılında da Bahar ve ark. tarafından Türkçe 'ye çevrilip, geçerlik- güvenirliği çalışılmıştır. Bu ölçek 52 madde ve altı faktörden oluşmaktadır. Bunlar manevi gelişim, kişiler arası ilişkiler, beslenme, fiziksel aktivite, sağlık sorumluluğu, stres yönetimidir. Alınan puanın yüksek olması sağlıklı yaşam biçimi davranışının olumlu olduğunun göstermektedir (14).

Ölçeğin genel puanı sağlıklı yasam biçimi davranışları puanını vermektedir. Ölçeğin tüm maddeleri olumludur. Derecelendirme 4'lü likert seklindedir. Hiçbir zaman (1), bazen (2), sık sık (3), düzenli olarak (4) şeklinde derecelendirilmiştir. Ölçeğin tamamı için en düşük puan 52, en yüksek puan 208'dir. Ölçeğin Cronbach Alpha katsayısı 0.92 olup yüksek güvenirlik derecesine sahiptir (14). Bu çalışmada ölçeğin güvenirlik katsayısı olan Cronbach Alpha katsayısı 0.925 olarak bulundu.

Öz-Bakım Gücü Ölçeği: Kearney ve Fleisher tarafından 1979 yılında geliştirilen öz-bakım gücü ölçeği 43 maddeden oluşmaktadır. Ölçek, Nahçıvan (1994) ve Pınar (1996) tarafından Türk toplumuna uyarlanmıştır. (16, 17). Bu araştırmada Nahcıvan (1994)'ın geliştirdiği ölçek kullanılmıştır (16). Ölçek beşli likert tipinde olup, her bir ifadeye sırasıyla 0, 1, 2, 3, 4 puan verilmektedir. Ölçekten alınacak minimum ve maksimum puan 0-136'dır. 0-23 puan çok kötü, 24-64 puan kötü, 65-100 puan orta, 101-112 puan iyi, 113-136 puan çok iyi olarak değerlendirilmektedir. Ölçeğin Cronbach Alpha katsayısı 0.92 olup yüksek güvenirlik derecesine sahiptir (16). Bu çalışmada ölçeğin güvenirlik katsayısı olan Cronbach Alpha katsayıs1 0.94 olarak bulundu.

Verilerin Değerlendirilmesi: Verilerin analizinde PASW 18 paket programı kullanıldı. Analiz sürecine geçilmeden önce verilerin normallik testleri kapsamında her bir bağımlı değişken düzeyinde dağılımların normallik gösterip göstermediği Kolmogorov-Smirnov normalite testi sonuçlarına bakıldı. Kolmogorov-Smirnov normallik testi analiz sonuçları, bağımlı değişkenler için tüm gruplarda normal dağılım göstermediği için non-parametrik testler kullanıldı. Elde edilen verilerin analizi sürecinde; tanımlayıcı istatistikler olarak frekans, yüzde, ortalama ve standart sapma, minimum, maksimum, ortanca ve çeyrekler arası aralık (ÇAA) değerleri ile birlikte Kruskal Wallis ve Mann-Whitney U testleri kullanıldı. İstatistiksel anlamlılık için $\mathrm{p}<0.05$ olarak kabul edildi. 
Araştırmanın Etiği: Araştırmanın yapılabilmesi için üniversite etik kurulundan (01.03.2016 tarih ve 27344949-020-13059 sayı numaralı) ve ilgili kurumlardan yazılı izin alındı. Araştırmaya katılan hastalara çalışmanın amaç ve yararları, çalışmadaki rolleri açıklanarak sözlü onamları alındı.

Araştırmanın Sınırlılıkları: Lomber disk hernisi nedeniyle hastaneye başvuran hastalar araştırma kapsamına alındı. Bu nedenle araştırma sonuçları sadece bu özellikleri taşıyan hastalara genellenebilir. Aynı zamanda araştırma verilerinin yüz yüze görüşme yöntemiyle toplanması nedeniyle verilerin güvenilirliği gönüllülerin verdikleri bilgilerle sınırlıdır.

\section{Bulgular}

Araştırmaya katılan hastaların yaş ortalaması 50.88 \pm 14.05 yıl (min:19-maks:86) ve \%54.2'si 41-60 yaş grubundaydı. Hastalardan \%73.8'inin kadın, \%36.7'sinin fazla kilolu, \%55.8'inin okuryazar veya ilköğretim mezunu olduğu saptandı. Araştırma grubunun \%46.3'ünün çalışmadığı, \%51.7'sinin ortalama gelir düzeyinde olduğu belirlendi. Katılımcıların lomber disk hernisi tanısı konulma zamanının ortalama $70.41 \pm 72.27$ ay (5.8 yıl) olduğu, \%39.02'sinin bel ağrısı şikayeti ile hastaneye başvurduğu, \%51.7'sinin daha önce lomber disk hernisine yönelik tedavi gördüğü ve bu tedavinin $\% 30.6$ oranda tıbbi tedavi olduğu belirlendi. Hastaların \%50.4'ünün lomber disk hernisi dışında kronik bir hastalığı vardı (Tablo 1).

Lomber disk hernili bireylerin SYBDÖ ve ÖBGÖ puan dağılımları Tablo 2'de gösterildi (Tablo 2). Hastaların SYBD ölçeği puan ortalamalarına bakıldığında; manevi gelişim alt grubu puan ortalaması $24.47 \pm 4.81$, kişilerarası ilişkiler alt grubu puan ortalaması $23.24 \pm 3.97$, beslenme alt grubu puan ortalaması $21.83 \pm 3.69$, sağl1k sorumluluğu alt grubu puan ortalamas $21.81 \pm 4.85$, stres yönetimi alt grubu puan ortalaması $18.33 \pm 4.11$, fiziksel aktivite alt grubu puan ortalaması $15.18 \pm 4.61$ ve SYBD ölçeği toplam puan ortalaması $125.09 \pm 21.05$ olarak bulundu. ÖBGÖ genel puan ortalaması $73.32 \pm 24.36$ olarak belirlendi, ölçekten alınan en düşük puanın 19, en yüksek puanın ise 140 olduğu belirlendi. 
Tablo 1. Hastaların sosyodemografik özellikleri $(\mathbf{n}=\mathbf{2 4 0})$

\begin{tabular}{|c|c|c|}
\hline Sosyodemografik Özellikler & $\mathbf{n}$ & $\%$ \\
\hline \multicolumn{3}{|l|}{ Yaş Grubu } \\
\hline \multicolumn{3}{|c|}{ Ort \pm SS: $50.88 \pm 14.05$, Ortanca (CAA): 52.5 (40.25-59.00), Min: 19, Maks: 86} \\
\hline 40 yas ve alt1 & 60 & 25.00 \\
\hline $41-60$ yaş & 130 & 54.2 \\
\hline 61 yaş ve üzeri & 50 & 20.8 \\
\hline \multicolumn{3}{|l|}{ Cinsiyet } \\
\hline Kadın & 177 & 73.8 \\
\hline Erkek & 63 & 26.3 \\
\hline \multicolumn{3}{|l|}{ Beden Kitle İndeksi } \\
\hline \multicolumn{3}{|c|}{ Ort \pm SS: $28.44 \pm 4.94$, Ortanca (ÇAA):28.40 (24.64-31.25), Min: 15.62, Maks:44.92 } \\
\hline Zayif $\left(<18.5 \mathrm{~kg} / \mathrm{m}^{2}\right)$ & 2 & 0.8 \\
\hline Normal $\left(18.5-24.9 \mathrm{~kg} / \mathrm{m}^{2}\right)$ & 63 & 26.3 \\
\hline Fazla kilolu $\left(25-29.9 \mathrm{~kg} / \mathrm{m}^{2}\right)$ & 88 & 36.7 \\
\hline Obez $\left(>30 \mathrm{~kg} / \mathrm{m}^{2}\right)$ & 87 & 36.3 \\
\hline \multicolumn{3}{|l|}{ Eăitim Düzevi } \\
\hline Okuryazar veya ilkokul & 134 & 55.8 \\
\hline Ortaokul & 10 & 4.2 \\
\hline Lise & 35 & 14.6 \\
\hline Üniversite & 61 & 25.4 \\
\hline \multicolumn{3}{|l|}{ Meslek } \\
\hline Calışmıyor & 111 & 46.3 \\
\hline Emekli & 42 & 17.5 \\
\hline Memur/işci/serbest & 87 & 36.2 \\
\hline \multicolumn{3}{|l|}{ Gelir Düzeyi } \\
\hline Ortalamanın üzerinde & 12 & 5.0 \\
\hline Ortalama düzeyde & 124 & 51.7 \\
\hline Ortalamanın altında & 104 & 43.3 \\
\hline \multicolumn{3}{|c|}{ Hastaneye Başvuru Şikayeti (birden fazla belirti işaretlenebilmiştir) } \\
\hline Bel ağris1 & 96 & 39.02 \\
\hline Bel ve bacak ağrısı & 56 & 22.76 \\
\hline Bacak ağrısı & 36 & 14.63 \\
\hline Güç kaybı & 11 & 4.47 \\
\hline Yürüyememe & 19 & 7.72 \\
\hline Bacakta uyusma & 28 & 11.38 \\
\hline \multicolumn{3}{|c|}{ Daha Önce Tedavi Görme Durumu } \\
\hline Evet & 124 & 51.7 \\
\hline Hayır & 116 & 48.3 \\
\hline \multicolumn{3}{|l|}{ Daha Önce Görülen Tedavi } \\
\hline Tibbi Tedavi & 38 & 30.6 \\
\hline Fizik Tedavi & 35 & 28.2 \\
\hline İlac ve fizik tedavi & 16 & 12.9 \\
\hline Ameliyat & 34 & 27.4 \\
\hline Alternatif Tedavi & 1 & 0.8 \\
\hline \multicolumn{3}{|c|}{ Baska Kronik Hastalık Olma Durumu } \\
\hline Olan & 121 & 50.4 \\
\hline Olmayan & 119 & 49.6 \\
\hline
\end{tabular}


Tablo 2. Hastaların Sağlıklı Yaşam Biçimi Davranışları Ölçeği ve Öz-Bakım Gücü Ölçeği Puan Dağılımları $(\mathrm{n}=240)$

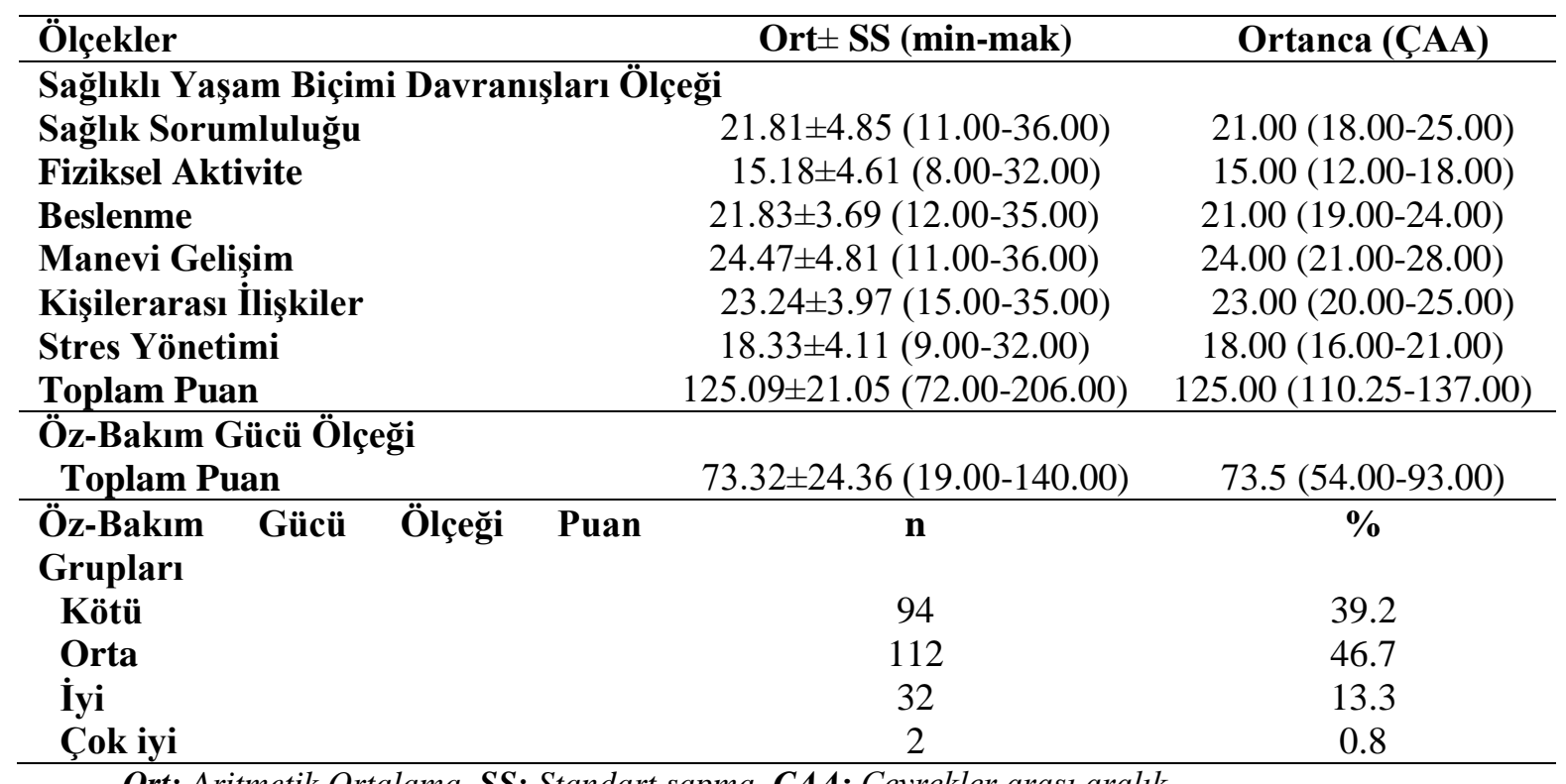

Lomber disk hernili bireylerin SYBDÖ ve ÖBGÖ puanının sosyodemografik özellikler ile karşılaştırılması Tablo 3'de belirtildi (Tablo 3).

Hastaların cinsiyet $(z=-1.39, p=0.162)$, eğitim düzeyi $\left(\chi^{2}=0.98, p=0.32\right)$, daha önce lomber disk hernisi ile ilgili tedavi görme durumu $(z=-1.24, \mathrm{p}=0.204)$ ve görülen tedavi çeşidi $\left(\chi^{2}=7.6\right.$, $\mathrm{p}=0.107$ ) ile SYBDÖ puanları arasında istatistiksel olarak anlamlı fark bulunmadı.

Çalışmaya katılan hastaların yaş grubu $\left(\chi^{2}=13.38, \mathrm{p}=0.001\right)$ ve beden kitle indeksi $\left(\chi^{2}=19.59\right.$, $\mathrm{p}=0.000)$ ile SYBDÖ puanları arasında istatistiksel olarak anlamlı fark saptandı. SYBDÖ puan ortalaması 40 yaş ve altında olan bireylerde daha yüksek bulundu. Beden kitle indeksi zayıf ve normal olan bireylerin SYBDÖ puanları fazla kilolu ve obez olan hastalara göre daha yüksekti. Meslek $\left(\chi^{2}=13.48, \mathrm{p}=0.001\right)$ ve gelir düzeyi $\left(\chi^{2}=16.67, \mathrm{p}=0.000\right)$ ile SYBDÖ puanları arasında istatistiksel olarak anlamlı fark olduğu saptandı. Çalışan ve gelir düzeyi ortalamanın üzerinde olan bireylerin SYBDÖ puanları daha yüksek bulundu. 
Tablo 3. Hastaların Ölçek Puanları ile Sosyodemografik Özelliklerinin Karşılaştırılması

\begin{tabular}{|c|c|c|c|}
\hline \multirow[t]{2}{*}{ Sosyodemografik Özellikler } & \multirow[t]{2}{*}{$\mathbf{N}$} & \multirow{2}{*}{$\begin{array}{c}\begin{array}{c}\text { Sağlıklı Yaşam Biçimi } \\
\text { Davranışları Ölçeği }\end{array} \\
\text { Ortanca(ÇAA) }\end{array}$} & \multirow{2}{*}{$\begin{array}{c}\text { Öz-Bakım Gücü Ölçeği } \\
\text { Ortanca(ÇAA) }\end{array}$} \\
\hline & & & \\
\hline $\begin{array}{l}\text { Yaş Grubu } \\
40 \text { yaş ve altı (a) }\end{array}$ & 60 & $133.00(117.25-144.00)$ & $80.00(60.00-103.75)$ \\
\hline $\begin{array}{l}41-60 \text { yaş }(\mathrm{b}) \\
61 \text { yaş ve üzeri (c) } \\
\chi^{2 * * / p} \\
\text { Çoklu Karşılaştırma }\end{array}$ & $\begin{array}{c}130 \\
50\end{array}$ & $\begin{array}{c}124.00(110.00-132.00) \\
115.00(106.75-134.00) \\
\chi^{2}=13.38, \mathbf{p}=\mathbf{0 . 0 0 1} \\
\mathrm{a}>\mathrm{b}>\mathrm{c}\end{array}$ & $\begin{array}{c}70.00(48.75-93.00) \\
78.50(60.50-91.25) \\
\chi^{2}=6.04 \mathbf{p}=\mathbf{0 . 0 4 9} \\
\mathrm{a}=\mathrm{c}>\mathrm{b}\end{array}$ \\
\hline $\begin{array}{l}\text { Cinsiyet } \\
\text { Kadın } \\
\text { Erkek } \\
\text { z*/p }\end{array}$ & $\begin{array}{l}177 \\
63\end{array}$ & $\begin{array}{c}125.00(108.00-137.00) \\
126.00(114.00-140.00) \\
z=-1.39, p=0.162\end{array}$ & $\begin{array}{c}72.00(51.00-93.00) \\
79.00(62.00-97.00) \\
\mathrm{z}=-1.55, \mathrm{p}=0.121\end{array}$ \\
\hline $\begin{array}{l}\text { Beden Kitle İndeksi } \\
\text { Zayıf }\left(<18.5 \mathrm{~kg} / \mathrm{m}^{2}\right)(\mathrm{a}) \\
\text { Normal }\left(18.5-24.9 \mathrm{~kg} / \mathrm{m}^{2}\right)(\mathrm{b}) \\
\text { Fazla kilolu }\left(25-29.9 \mathrm{~kg} / \mathrm{m}^{2}\right)(\mathrm{c}) \\
\text { Obez }\left(>30 \mathrm{~kg} / \mathrm{m}^{2}\right)(\mathrm{d})\end{array}$ & $\begin{array}{c}2 \\
63 \\
88 \\
87\end{array}$ & $\begin{array}{l}163.50(163.00-163.50) \\
130.00(125.00-140.00) \\
121.00(111.00-136.00) \\
120.00(105.00-134.00)\end{array}$ & $\begin{array}{c}120.50(117.00-120.00) \\
70.00(55.00-93.00) \\
77.50(50.25-89.75) \\
73.00(54.00-93.00)\end{array}$ \\
\hline $\begin{array}{l}\chi^{2 * * / p} \\
\text { Çoklu Karşılaştırma }\end{array}$ & & $\begin{array}{c}\chi^{2}=19.59, \mathbf{p}=\mathbf{0 . 0 0 0} \\
a>b>c=d\end{array}$ & $\chi^{2}=6.143, p=0.105$ \\
\hline $\begin{array}{l}\text { Eğitim Düzeyi } \\
\text { Okuryazar veya ilkokul } \\
\text { Ortaokul } \\
\text { Lise } \\
\text { Üniversite } \\
\chi^{2 * * / p}\end{array}$ & $\begin{array}{l}134 \\
10 \\
35 \\
61\end{array}$ & $\begin{array}{c}123.00(108.00-137.00) \\
111.00(109.00-127.00) \\
125.00(114.00-140.00) \\
128.00(115.50-144.00) \\
\chi^{2}=0.98, \mathrm{p}=0.32\end{array}$ & $\begin{array}{l}70.50(50.00-88.00) \\
71.00(62.00-91.00) \\
77.00(45.00-97.00) \\
81.00(58.50-99.00) \\
\chi^{2}=0.241, \mathrm{p}=0.623 \\
\end{array}$ \\
\hline $\begin{array}{l}\text { Meslek } \\
\text { Çalışmı̀yor (a) } \\
\text { Emekli (b) } \\
\text { Memur/işçi/serbest (c) } \\
\chi^{2 * * / p} \\
\text { Çoklu Karşılaştırma } \\
\end{array}$ & $\begin{array}{l}111 \\
42 \\
87\end{array}$ & $\begin{array}{c}117.00(108.00-131.00) \\
125.00(121.50-137.75) \\
128.00(115.00-144.00) \\
\chi^{2}=13.48, \mathbf{p}=\mathbf{0 . 0 0 1} \\
\mathrm{a}>\mathrm{b}=\mathrm{c}\end{array}$ & $\begin{array}{c}67.00(50.00-88.00) \\
80.50(46.00-95.00) \\
77.00(60.00-98.00) \\
\chi^{2}=6.68, \mathbf{p}=\mathbf{0 . 0 3 5} \\
\mathrm{b}>\mathrm{c}>\mathrm{a}\end{array}$ \\
\hline Gelir Düzeyi & & & \\
\hline $\begin{array}{l}\text { Ortalamanın üzerinde } \\
\text { Ortalama düzeyde } \\
\text { Ortalamanın altında } \\
\chi^{2 * * / p}\end{array}$ & $\begin{array}{l}12 \\
124 \\
104\end{array}$ & $\begin{array}{c}133.00(128.00-138.00) \\
126.00(118.25-137.75) \\
114.00(107.00-132.75) \\
\chi^{2}=16.67, \mathbf{p}=\mathbf{0 . 0 0 0}\end{array}$ & $\begin{array}{c}75.00(45.00-95.00) \\
70.00(50.00-94.00) \\
75.50(58.50-93.00) \\
\chi^{2}=0.92, \mathrm{p}=0.631\end{array}$ \\
\hline $\begin{array}{l}\text { Daha Önce Tedavi Görme Dur } \\
\text { Evet }\end{array}$ & 124 & $125.00(110.00-137.00)$ & $70.00(51.00-88.00)$ \\
\hline $\begin{array}{l}\text { Hayır } \\
\mathbf{z}^{* / \mathbf{p}}\end{array}$ & 116 & $\begin{array}{c}125.00(111.00-140.00) \\
\mathrm{z}=-1.24, \mathrm{p}=0.204\end{array}$ & $\begin{array}{c}79.00(55.50-97.00) \\
z=-2.30, \mathbf{p}=\mathbf{0 . 0 2 2}\end{array}$ \\
\hline $\begin{array}{l}\text { Daha Önce Görülen Tedavi } \\
\text { T1bbi Tedavi } \\
\text { Fizik Tedavi } \\
\text { İlaç ve fizik tedavi } \\
\text { Ameliyat } \\
\text { Alternatif Tedavi } \\
\chi^{2 * * / p}\end{array}$ & $\begin{array}{l}38 \\
35 \\
16 \\
34 \\
1\end{array}$ & $\begin{array}{c}115.00(108.00-125.00) \\
126.00(106.00-144.00) \\
127.50(111.50-137.00) \\
126.00(113.00-144.00) \\
123.00(123.00-123.00) \\
\chi^{2}=7.6, p=0.107\end{array}$ & $\begin{array}{l}72.00(51.00-88.00) \\
76.00(55.00-93.00) \\
58.00(44.00-85.00) \\
69.50(45.00-83.00) \\
76.00(76.00-76.00) \\
\chi^{2}=2.3 \mathrm{p}=0.68\end{array}$ \\
\hline $\begin{array}{l}\text { Başka Kronik Hastalık Olma } \\
\text { Olan } \\
\text { Olmayan }\end{array}$ & $\begin{array}{l}121 \\
119\end{array}$ & $\begin{array}{l}120.00(106.50-137.50) \\
126.00(114.00-137.00)\end{array}$ & $\begin{array}{l}73.00(54.00-93.00) \\
55.50(76.00-97.00)\end{array}$ \\
\hline $\mathbf{z}^{* / \mathbf{p}}$ & & $\mathrm{z}=-2.55, \mathbf{p}=\mathbf{0 . 0 1 1}$ & $\mathrm{z}=-0.627, \mathrm{p}=0.531$ \\
\hline
\end{tabular}

Ort: Aritmetik Ortalama, SS: Standart sapma, ÇAA: Çeyrekler arası aralık, $p<0.005, \boldsymbol{x}^{2 * * *}$ Kruskall Wallis testi, $z^{*}$ Mann Whitney U testi, 
Lomber disk hernisi hastalığı dışında kronik bir hastalığın olması durumu ile SYBDÖ puan ortalamaları arasında istatistiksel olarak anlamlı fark olduğu saptandı $(z=-2.55, p=0.011)$. Kronik bir hastalığı olmayan bireylerin SYBDÖ puanlarının daha yüksek olduğu belirlendi. Hastaların öz-bakım gücü ile sosyodemografik özellikleri karşılaştırıldığında yaş grubu $\left(\chi^{2}=6.04 \mathrm{p}=0.049\right)$, meslek $\left(\chi^{2}=6.68, \mathrm{p}=0.035\right)$ ve lomber disk hernisi ile ilgili tedavi görme durumu $(z=-2.30, \mathrm{p}=0.022)$ ile ÖBGÖ puanları arasında istatistiksel olarak anlamlı fark saptand1.

\section{Tartışma}

Araştırmaya katılan hastaların yarısından fazlası 40 yaşın üstündedir. Lomber disk hernisi ile ilgili yapılan araştırmalarda hastaların yaş ortalaması bu çalışmaya benzer olarak 45-50 yaş aralığındadır $(9,11,12)$. Bulgular lomber disk hernisinin orta yaşlı üretken bireylerde görülme oranının yüksek olduğunu destekler niteliktedir.

Araştırma grubunun yarısından fazlasını şişman ve aşırı şişman hastalar oluşturdu. Fazla kilo ve beden kitle indeksinin yüksek olmasının lomber disk hernisi için risk faktörlerinden olduğu bilinmektedir $(2,3,4,6,7)$. Konu ile ilgili yapılan çalışmalarda lomber disk hernisi olan hastaların çoğunun şişman hastalar olduğu belirtilmiştir $(11,12)$. Araştırma bulguları literatür bulguları ile paralellik göstermektedir. Obezitenin lomber bölgedeki yükü arttırması ve postüral bozukluklara yol açmasına bağlı olarak lomber disk hernisi riskini arttığı bilinmektedir (2, 4, 7).

Çalışmaya katılan hastaların hastaneye başvuru sebeplerinin başında bel ağrısı şikayetinin geldiği saptandı. Literatürde de benzer olarak lomber disk hernisi olan hastaların en fazla ağrı şikayetiyle hastaneye başvurduğu görülmektedir $(7,18,19)$. Hastaların yaşadığı bu semptomlar lomber disk hernisinde oluşan sinir basısı nedeniyle ortaya çıkan sorunlardır.

Disk hernilerinde farklı tedavi yöntemleri bulunmaktadır. Akut dönemde yatak istirahati, analjezik-antiinflamatuar, kas gevşetici ilaçlar, B vitamini (parestezik semptomlarda), sıcak uygulama, boyunluk kullanılması, boyun egzersizleri, traksiyon vb. gibi konservatif tedavi yöntemlerden hasta yarar görür. Konservatif tedaviye cevap alınamayan veya bulguların ilerlediği durumlarda; cerrahi tedavi uygulanır (5). Çalışmaya alınan hastaların lomber disk hernisi tedavisinde; tıbbi tedavi, fizik tedavi ve ameliyat olma durumları yakın oranlarda bulunmuştur. Araştırmaya dahil edilen hasta grubunu Beyin ve Sinir Cerrahisi Kliniğine 
başvuran hastalar oluşturduğu için ameliyat olan hastaların oranı sayıca fazla olup diğer tedavi yöntemlerine yakındır.

Sigara içme, fiziksel aktivite, sağlıklı beslenme ve 1lımlı alkol kullanımı gibi yaşam tarzı faktörleri hastalığın riskini ve seyrini etkileyen durumlardır. Sağlıklı yaşam biçimi davranışlarının sağlık problemlerini ve mortaliteyi etkileme potansiyeli yüksektir (20). Bohman ve ark. (2014) tarafından yapılan bir kohort çalışmasında sağlıklı yaşam biçimi (sigara içmeme, önerilen fiziksel aktivite seviyesi, dengeli beslenme gibi) olan kadınların bel ağrısı görülme riskinin \%35 azaldığı belirtilmiş, erkek hastalar için de sonuçlar aynı eğilimi göstermiştir (20). Skillgate ve ark. (2017) tarafından yapılan çalışmada da benzer şekilde sağlıklı yaşam biçiminin uzun dönem bel ağrısında önleyici faktör olduğu gösterilmiştir (21).

Çalışmamızda lomber disk hernisi olan hastaların SYBDÖ puan ortalamasının orta düzey olduğu (125.09 \pm 21.05$)$ ve en düşük puan ortalamasının egzersiz yapma alt boyutu olduğu saptandı. Hipertansiyon, koroner arter hastalığ gibi kronik hastalığı olan bireylerde yapılan çalışmalarda da SYBDÖ puan ortalamasının orta düzey olduğu belirtilmiştir $(22,23)$.

Çalışmada yaş, beden kitle indeksi, sosyoekonomik durum, kronik hastalık varlığı sağlıklı yaşam biçimini etkileyen faktörler olarak bulundu. Beden kitle indeksi yüksek olan hastaların SYBD puan ortalamaları zayıf ve normal kilolu olan hastalara göre daha düşüktü. Fazla kilolu ve obez bireylerde aktivite kısıtlılıkları, aktivite intoleransı, sağlıksız beslenme gibi faktörlerin genel sağlıklı yaşam biçimi davranışlarını etkilediği düşünülmektedir.

Çalışmamızın sonuçlarına baktığımızda SYBDÖ fiziksel aktivite alt boyut puan ortalaması dışında diğer boyutların puan ortalamaları ortanca değerden yüksek bulunmuştur. Yapılan diğer çalışmalarda fiziksel aktivite boyutu düşük bulunmuş olup çalışmamızı destekler niteliktedir $(22,23)$. Lomber disk hernisi'nin hastanın fiziksel aktivite düzeyini doğrudan etkileyen bir hastalık olmasından dolayı, bu alt boyutta alınan puanın düşük olması beklenen bir durumdur.

Lomber disk hernisi; hastaların fiziksel fonksiyonlarını, günlük yaşam aktivitelerini ve özbakımını olumsuz yönde etkiler $(2,6,8,9)$. Çalışmamızda araştırmaya katılan hastaların özbakım gücü orta düzeyde bulundu. Lomber disk hernisi olan hastalarda öz-bakım gücünü inceleyen çalışmalar da benzer şekilde öz-bakım gücünü orta düzeyde bulmuştur $(12,24)$. Farklı hastalıklarda da öz- bakım gücünü inceleyen araştırmalar da bulunmaktadır $(25,26,27$, 28, 29, 30). Bu çalışmalarda da öz-bakım gücü orta düzeyde saptanmıştır. Lomber disk hernisi 
olan hastaların yaş ortalamasının orta ve yüksek olması, günlük yaşam aktivitelerini gerçekleştirmek için yardıma ihtiyaç duymaları, ağrı yaşamaları ve fiziksel hareket kısıtlılıklarının olması öz-bakım gücünü orta düzey bulunmasında etkili sebepler olarak gösterilebilir.

Literatürde hastaların yaş ile öz-bakım gücünü ilişkilendiren çalışmalarda farklı sonuçlar bildirilmiştir. Yaş arttıkça öz-bakım gücünün arttığı çalışmaların yanı sıra yaşın ilerlemesiyle öz-bakım gücünün azaldığını gösteren çalışmalar da bulunmaktadır $(25,30)$. Ayrıca yaş ve özbakım gücü arasında ilişki olmadığını belirten çalışmalar da mevcuttur $(26,27)$. Bu farklılığın hastalığın türü, şiddeti, süresi gibi çeşitli etkenlerden kaynaklandığı düşünülmektedir. Bu çalışmada genç yaş grubunda olan hastaların öz bakım gücü en yüksek oranda bulundu.

\section{Sonuç}

Araştırma sonucunda; hastaların öz-bakım gücünün ve sağlıklı yaşam biçimi davranışlarının orta düzeyde olduğu belirlendi. Lomber disk hernisinin fiziksel aktivite seviyelerini olumsuz yönde etkilediği saptandı. $\mathrm{Bu}$ bağlamda, hastalara ağrı düzeylerini ve fonksiyonel yetersizliklerini azaltıp, yaşam kalitelerini arttırmaya yönelik girişimlerin planlanması ve uygulanması önerilmektedir.

Bu çalışma 8-12 Nisan 2016 tarihinde düzenlenen Nöroşirurji Hemşireliği Derneği 12. Bilimsel Kongresi'nde Sözel bildiri olarak sunulmuştur.

\section{Kaynaklar}

1. Amin RM, Andrade NS, Neuman BJ. Lumbar disc herniation. Curr Rev Musculoskelet Med 2017; 10: 507.

2. Sarı S, Aydoğan M. As a common cause of back pain: lumbar disc herniation. TOTBiD Journal 2015; 14:298304.

3. Zileli M, Gülmen V. Lomber disk hernisinde yakınma ve bulgular. Zileli M, Özer AF, editörler. Omurilik ve Omurga Cerrahisi, 2. Bask1. İzmir: Meta Basım; 2002:635-46.

4. Özbayır T. Nörolojik travmalar. Karadakovan A, Eti Aslan F, editör. Dahili ve Cerrahi Hastalıklarda Bakım, 2. Bask1. Adana: Nobel Kitabevi; 2014:1275-84. 
5. Çetinkaya MY. Disk hernisi cerrahisi ve hemşirelik bakımı. Turkiye Klinikleri J Surg Nurs-Special Topics 2015;1(2):100-6.

6. Resnik L, Dobrykowski E. Outcomes measurement for patients with low back pain. Orthop Nurs 2005; 24:1424.

7. Dönmez YC, Dolgun E, Kabataş M, Özbayır T. Lomber disk hernili hastalarda risk faktörlerinin incelenmesi. F.Ü.Sağ.Bil.Tıp Derg. 2010; 24 (2): 89 - 92.

8. Wood SL, Douphine SL. Assessment of back-related quality of life: the continuing challenge. Spine 2001;26:857-861.

9. Köçkar Ç, Uzun Ö. Lomber disk herni ameliyatı olan hastalarda algılanan sosyal destek ile yaşam kalitesi arasındaki ilişkinin incelenmesi. Atatürk Üniversitesi Hemşirelik Yüksekokulu Dergisi 2007; 10(4):30-41.

10. Kagaya H, Takahashi H, Sugawara K, Kuroda T, Takahama M. Quality of life assessment before and after lumbar disc surgery. J Orthop Sci. 2005;10(5):486-9.

11. Yılmaz E, Çeçen D, Temiz C, Mutlu S, Kızıl Toğaç H, Aslan A, Kara H. Lomber disk hernisi olan bireylerde fonksiyonel yetersizlik ve fiziksel aktivite düzeylerinin yaşam kalitesi ile ilişkisi. CBU-SBED $2018 ; 5$ (2): 38-43.

12. Irmak B, Bölükbaş $N$ (Danışman). Lomber disk herni nedeniyle ameliyat olan hastalarda hastalık algısının öz-bakım gücüne etkisi. Ordu Üniversitesi Sağlık Bilimleri Enstitüsü, Hemşirelik Anabilim Dalı. Yüksek Lisans Tezi, 2016.

13. Walker SN, Hill-Polerecky DM. Psychometric evaluation of the Health Promoting Lifestyle Profile II. Unpublished manuscript, University of Nebraska Medical Center,1996.

14. Bahar Z, Beşer A, Gördes N, Ersin F, Kıssal A. Sağlıklı Yaşam Biçimi Davranışları Ölçeği II’nin geçerlik ve güvenirlik çalışması. C.Ü. Hemşirelik Yüksekokulu Dergisi 2008; 12(1):1-13.

15. Kearney BY, Fleischer BJ. Development of an instrument to measure exercise of selfcare agency. Res Nurs Health 1979; 2(1):25-34.

16. Nahcıvan N. Geçerlik ve güvenirlik çalışması: Öz-Bakım Gücü Ölçeğinin Türkçe’ye uyarlanması. Hemşirelik Bülteni 1994;7 (33):109-119.

17. Pınar R. Diyabetes mellituslu hastalarda özbakım gücü, özbakım gücü ile sosyo-demografik ve klinik değişkenler arasındaki ilişki. Türk Diyabet Yıllığı 1996;248.257.

18. Akca NK, Aydın G, Gümüş K. Lomber disk hernili hastaların vücut mekanikleri bilgi düzeyleri ile ağrı şiddeti arasındaki ilişki. Gümüşhane Üniversitesi Sağlık Bilimleri Dergisi 2013; 2(1), 66-77.

19. Çıkrıkçığlu HY, Yılmaz E. Lomber disk hernili hastalarda fonksiyonel yetersizlik ve yaşam kalitesinin ameliyata karar verme sürecine etkisi. 9. Ulusal Türk Cerrahi ve Ameliyathane Hemşireliği Kongre Kitabı, 2015;252.

20. Bohman T, Alfredsson L, Jensen I, Hallqvist J, Vingård E, Skillgate E. Does a healthy lifestyle behaviour influence the prognosis of low back pain among men and women in a general population? A population-based cohort study. BMJ Open 2014;4:e005713.

21. Skillgate E, Pico-Espinosa OJ, Hallqvist J, Bohman T, Holm LW. Healthy lifestyle behavior and risk of long duration troublesome neck pain or low back pain among men and women: results from the Stockholm Public Health Cohort. Clin Epidemiol. 2017; 9:491-500. 
22. Şahin T, Borlu A (Danışman). Adıyaman il merkezinde 15-49 yaş kadınlarda obezite sıklı̆̆ı, fiziksel aktivite düzeyi ve sağlıklı yaşam biçimi davranışları. Erciyes Üniversitesi Sağlık Bilimleri Enstitüsü, Halk Sağlığı Anabilim Dalı. Doktora Tezi, 2018.

23. Şerifoğulları Z, Yurtsever S (Danışman). Koroner arter hastalığı olan bireylerin hastalık algıları ile sağlıklı yaşam biçimi davranışları arasındaki ilişki. Mersin Üniversitesi Sağlık Bilimleri Enstitüsü, Hemşirelik Anabilim Dalı. Yüksek Lisans Tezi, 2018.

24. Sarıtaş S, Karabulut N (Danışman). Lomber disk hernisi ameliyatı olan hastalara verilen eğitimin yaşam kalitesi öz-bakım gücü ve cinsel doyum üzerine etkisi. Atatürk Üniversitesi Sağlık Bilimleri Enstitüsü, Cerrahi Hastalıkları Hemşireliği Anabilim Dalı. Doktora Tezi, 2011.

25. Cebeci F, Şenol Çelik S (Danışman). Koroner arter bypass greft ameliyatı geçiren hastalara verilen taburculuk eğitimi ve danışmanlık hizmetinin öz-bakım gücüne, anksiyete ve depresyon durumuna etkisi. Hacettepe Üniversitesi Sağlık Bilimleri Enstitüsü, Cerrahi Hastalıkları Hemşireliği Anabilim Dalı. Yüksek Lisans Tezi, 2004.

26. Üstündağ H, Zengin N. Baş boyun kanseri nedeni ile cerrahi girişim geçiren hastaların öz-bakım gücünün değerlendirilmesi. Atatürk Üniversitesi Hemşirelik Yüksekokulu Dergisi 2008;11(1): 63-68.

27. Bıçakçı H, Ege E (Danışman). Doğum sonrası annelerin öz-bakım gücünün hastane taburculuğuna hazır oluşluklarına etkisi. Selçuk Üniversitesi Sağlık Bilimleri Enstitüsü, Hemşirelik Anabilim Dalı. Yüksek Lisans Tezi, 2010.

28. Gün Ç, Kömürcü N (Danışman). Histerektomili hastalarda benlik saygısının öz-bakım gücüne etkisi. Marmara Üniversitesi Sağlık Bilimleri Enstitüsü, Doğum ve Kadın Hastalıkları Hemşireliği Anabilim Dalı. Yüksek Lisans Tezi, 2011.

29. Nart M, Kanan N (Danışman). Açık kalp ameliyatı sonrası mobilize olan hastalarda öz-bakım gücünün değerlendirilmesi. Haliç Üniversitesi Sağlık Bilimleri Enstitüsü, Hemşirelik Anabilim Dalı. Yüksek Lisans Tezi, 2013.

30. Eraydın C, Sunal S (Danışman). Stomalı hastalarda öz bakım gücünün belirlenmesi. İstanbul Medipol Üniversitesi Sağlık Bilimleri Enstitüsü, Hemşirelik Anabilim Dalı. Yüksek Lisans Tezi, 2016. 